\title{
VOCÊS NÃO PODEM ADIAR MAIS OS NOSSOS SONHOS...
}

\author{
ALZIRA RUFINO \\ Casa de Cultura da Mulher Negra
}

A organização política das mulheres negras para a Conferência Mundial contra o Racismo, a indicação de uma mulher negra sul-africana, Dlami Zuma, para a presidência da Conferência, de uma brasileira negra/Edna Roland, para a relatoria e a visibilidade crescente das mulheres nas Gonferênclas Mundiais são sinais do poder feminino na transformação do planeta.

Durban foi e está sendo um processo de aprendizado da nossa capacidade de ações e concretizações. Durante dois anos, ou mais, engenheiras e engenheiros da construção encaminharam esse estressante processo para que mais de 600 pessoas estivessem no ar, no mar, na terra de Durban, África.

Ações coordenadas, supperando as nossas diferenças e indiferenças em um espaço comum.

Na preparação da Conferência no Brasil, muitos/as não perceberam a importância de ir a Durban com uma delegação expressiva. Priorizava-se a qualidade na mão de alguns e algumas. Por que uma delegação de 600 e não de 50, ou menos?

Ora, por que enfiar a massa nessa história?

Porque era um fato único, Conferência Mundial contra o racismo não acontece todo dia e precisava ter atores e atrizes com a cara do povo brasileiro discriminado.

Mostrar para o mundo que somos muitos/as e que o racismo brasileiro não está só na cabeça de alguns/as. Essa luta é propriedade nossa, de todo um povo.

Se com 600 pessoas na delegação conseguimos pouca visibilidade no cenário de Durban, o que dizer de uma representação tímida?

Não se faz um comício, uma passeata sem povo. Não se toca um violão sem cordas.

A organização dos palestinos em Durban mostrou o poder de pressão de um grupo coeso, agindo em uníssono.

É óbvio que o Brasil, ao levar a maior delegação à Conferência Mundial, deu um recado mais forte, e mais forte teria sido se não tivesse havido tantas reuniões de portas fechadas, informações retidas nas mãos de alguns/algumas, negociações não debatidas e a história contada pela metade.

Tivemos alguns acertos e inúmeras falhas nessa caminhada: abuso de poder, informações truncadas, falta de habilidade de mexer a massa.

É evidente também que a pouca comunicação e informação, as falhas de infraestrutura para a participação brasileira na preparação e durante o evento foram uma imaturidade que não temos o direito de repetir, a não ser por burrice e incompetência, mas isso também foi um aprendizado. 


\section{Pé que não dá topada não cria calo}

Sabemos que o processo de construção não se faz de uma maneira fácil e rápida.

Ainda temos que aprender a negociar nossas idéias e nossas ações de uma maneira mais harmônica e conjunta, respeitando as habilidades de cada um/a na planta da obra.

Socializar e democratizar são verbos para serem conjugados por todos/as. Precisamos evitar desentendimentos pessoais em processos dessa importância. Não podemos mais egoisticamente excluir nossos/as desafetos/as pessoais. Em uma conferência em país estrangeiro, sentimos isso.

Precisamos repensar a nossa estratégia nos passos que daremos adiante para que a Conferência de Durban não tenha morte súbita sem diagnóstico.

Política se faz com a razão e sentando à mesma mesa governo, movimentos, ONGs, legisladores/as, para podermos ter um fio condutor para plugar e agilizar esse processo.

Repetindo a mesma frase, fazer política não só com o fígado, mas com a cabeça, trabalhando a união e as diferenças em uma mesma mesa. Conduzindo esse processo de uma maneira mais madura, conseguiremos chegar a um consenso que precisaríamos estar fortalecendo.

Reuniões, financiadores, discussões, desacertos, esperanças, dúvidas nos levaram a acreditar que é preciso coragem para mostrar ao mundo que nós negros/as dessa parte do planeta chamada Brasil estamos com o nosso grito na garganta e para desmistificar representantes que passaram para o mundo que o Brasil é um país onde existe a democracia racial.

O pouco envolvimento da sociedade e das organizações não-negras em uma conferência tão importante mostrou-nos que quando falamos de racismo e de políticas afirmativas ainda estamos por nossa conta.

Na abertura da Conferência de Durban, o presidente Thabo Mbeki referiu-se à sociedade sul-africana pós-apartheid dizendo: "Podemos não estar uns contra os outros na luta contra o apartheid - mas também não estamos uns com os outros". As palavras se aplicam bem à sociedade racial brasileira.

O Brasil, ao lado da Guatemala e de Honduras, figura entre os países com os mais elevados níveis de discriminação e injustiça racial no mundo. Está lá, no documento preparado pela Anistia Internacional para a Conferência Mundial contra o Racismo e a Discriminação.

Também está no documento da Anistia o que já sabemos: "Apesar da lei anti-racista aprovada no País em 1997, poucos casos de racismo chegam ao tribunal".

Virando o jogo, com pesquisas fundamentadas, desnudamos a posição social, econômica da população afrodescendente no Brasil. O Instituto de Pesquisa Econômica Aplicada (IPEA) confirma: somos $68 \%$ de todos os pobres do País e precisamos de ações urgentes, para mais da metade da população dos sobreviventes do racismo, da pobreza brasileira.

É preciso que 'urgenciemos' o processo brasileiro para que nossos/as legisladores/ as, $O A B$, organizações negras, de mulheres e sindicatos lancem um olhar de lupa nos capítulos, parágrafos, incisos, recomendações, disposições transitórias e comecem a tirar do papel esse processo.

O papel tudo aceita.

Na etapa final da Conferência e com o impacto da discussão das cotas, conseguimos fazer com que o grande público e a mídia discutissem o racismo. 
As falas das autoridades na hora do palanque e dos holofotes devem ser usadas, reproduzidas, incluídas em nossas cobranças. Não poderemos deixar que esses documentos de promessas façam parte do museu, do centro de documentação das coisas definitivamente passadas.

Isso é responsabilidade nossa, mas não podemos cometer os mesmos erros de quem tem acesso a tais informações, trancando-as no seu guarda-roupa à chave, dizendo-se proprietário/a das informações, do documento.

Se não houver cumplicidade entre as entidades negras, nós não chegaremos a lugar nenhum.

É tempo de ensinar o que sabemos fazer bem e aprender o que nos falta.

Conhecer o que cada um/a está fazendo em sua região, trocar conhecimentos. E isso só coletivamente se consegue.

Essa sensibilização tem que sair das reunióes do movimento e ir para a rua, para o pagode, para onde o povo negro está. Há muito/a jovem aí.

Se os partidos políticos se organizam, se as igrejas se organizam e obtêm respostas, nós, raça negra, maioria da população, também podemos.

Para isso, primeiro, é preciso superar o caciquismo, as desconfianças, sentar com humildade a uma mesa de reunião e trabalharmos juntos para que a coisa dê certo, porque do jeito que está não está bom.

Tivemos o processo de Viena, dos Direitos Humanos, tivemos o processo de Beijing, agora a Conferência contra o racismo. Avançamos mas ainda é pouco. É só ver nossa preparação para o Fórum Social Mundial, em Porto Alegre, no início de 2002, para constatarmos as fragilidades da nossa mobilização negra. Falta de conjunto.

Isso requer comunicação e unidade de ação.

O que diremos em Durban +5 ?

Estamos entrando em um ano eleitoral. Em nível estadual e nacional, precisamos de candidaturas e plataformas partidárias compromissadas. Já é tempo para que a reserva de cotas para candidatas mulheres seja estendida a candidatos/as afrodescendentes.

Nossa mobilização será necessária para podermos enfrentar as dificuldades que nos aguardam. Política não se faz sozinho/a. Vamos abrir o leque de compromisso com educadores/as, famílias, igrejas, sindicatos.

Vamos passar da falação para a pressão. Exigindo, boicotando, excluindo do nosso voto, do nosso consumo.

Aprender a negociar com nosso poder de maioria. Vale lembrar: o sistema de cotas e outras ações afirmativas reivindicadas pelas organizações negras não vão beneficiar uma minoria, mas uma população afro-brasileira de mais de 72 milhões de habitantes, a segunda maior população negra do mundo depois da Nigéria.

Não vamos falar como maioria; vamos agir como a maioria que de fato somos.

Pré-condição: para termos poder político, o povo afrodescendente precisa estar no mesmo trem. Ser informado e convidado a participar.

E, mais uma vez, falamos de comunicação e informação.

Precisamos de ousadia. Nossas ações ainda são muito tímidas. Fazer um grande estardalhaço, escandalizar com dados, campanhas, grandes marchas, vigílias, materiais com slogans (sugestão: "Você não é racista, certo?").

Envolver jornalistas, publicitários/as, empresários/as na luta contra a discriminação e a intolerância.

Falando não de-nós-para-nós-do-movimento, mas falando do movimento para a comunidade afro-brasileira e a sociedade. Nossos/as comunicadores/as precisam deixar 
de querer sombra e água fresca, sapato folgado e jornal sem letra. Vamos trabalhar, gente boa!

Não dá para colocar as informações no cofre. Informação é poder, é política, é fermento.

Os resultados desta Conferência têm que estar na boca do povo. Sem comunicação, a massa não cresce...

Um sonho que se sonha junto não é um sonho apenas; é realidade.

Por outro lado, o nosso poder político precisa do nosso poder econômico.

Mais uma vez, falaremos da urgência de nos fortalecermos economicamente. Não se elegem candidatos/as negros/as apenas com idéias, palavras e boas intenções.

Não teremos empresários/as negros/as compromissados/as se não percebermos a importância de uma economia negra forte e apoiarmos as iniciativas de quem se joga na competição de mercado com coragem.

Não podemos jamais esquecer que as empresas negras têm tudo jogando contra. Se nós não as apoiarmos, quem apoiará?

E se não sabemos administrar uma empresa, formal ou informal, temos que aprender com urgência. Sinal dos tempos.

Aliás, em um tempo em que as agências de cooperação estão se dirigindo para outras prioridades fora do Brasil, precisamos pensar em alternativas de fortalecimento econômico das próprias ONGs negras, inclusive.

Ao concluir, não podemos deixar de mencionar que, resgatando nossas ancestrais africanas, as mulheres negras estão evidenciando a sua liderança na hierarquia da organização quilombola.

Incansáveis, ousadas, superando limites...

É urgente aumentar o número de mulheres negras, no Legislativo e no Executivo, dando voz, hoje, a essa vasta população feminina que é negra. Quando as cotas de candidaturas femininas serão, finalmente, repartidas? A adoção de uma cota para mulheres negras deverá, a médio prazo, contribuir para o desenvolvimento das lideranças femininas negras que poderão dar representação política às mulheres negras dentro da esfera do poder.

Nós, mulheres negras, somos a maioria da população feminina, conhecemos o nosso lugar.

Vocês não podem adiar mais os nossos sonhos... 